\title{
PHF20 inhibition promotes apoptosis and cisplatin chemosensitivity via the OCT4-p-STAT3-MCL1 signaling pathway in hypopharyngeal squamous cell carcinoma
}

\author{
XIUXIU LIU ${ }^{1,2^{*}}$, ZHANCHENG ZHANG ${ }^{1,3^{*}}$, SHIFENG KAN ${ }^{1,2}$, ZHENGHUA LV ${ }^{1,2}$, \\ SHENGLI ZHOU ${ }^{1,2}$, XIANFANG LIU ${ }^{1,2}$, PEIHANG JING ${ }^{1}$ and WEI XU ${ }^{1,2}$ \\ ${ }^{1}$ Department of Otorhinolaryngology, Head and Neck Surgery, Shandong Provincial ENT Hospital, \\ Cheeloo College of Medicine, Shandong University, Jinan, Shandong 250012; \\ ${ }^{2}$ Shandong Provincial Key Laboratory of Otology, Jinan, Shandong 250022; \\ ${ }^{3}$ Department of Otorhinolaryngology, The Fourth Hospital of Jinan, Jinan, Shandong 250031, P.R. China
}

Received December 5, 2020; Accepted April 12, 2021

DOI: $10.3892 /$ ijo.2021.5218

\begin{abstract}
Cisplatin is a widely used platinum-based chemotherapeutic agent for hypopharyngeal squamous cell carcinoma (HSCC). However, resistance to cisplatin limits its use for the treatment of HSCC, and the underlying molecular mechanism requires further investigation. The present study performed functional assays to determine whether the expression of plant homeodomain finger protein 20 (PHF20) may be involved in the apoptosis and cisplatin resistance of HSCC. The expression levels of PHF20 were higher in cisplatin-resistant HSCC cells compared with those in cisplatin-sensitive cells. The inhibition of PHF20 suppressed cell viability but did not affect the migratory and invasive abilities of HSCC cells compared with those of negative control-transfected cells. Furthermore, PHF20 inhibition reduced cell viability by enhancing apoptosis compared with those in the control cells in vitro. Notably, the inhibition of PHF20 sensitized HSCC cells to cisplatin, thus increasing apoptosis via the signal transducer and activator of transcription 3 (STAT3)-myeloid cell leukemia-1 (MCL1) pathway. Octamer-binding transcription factor 4 (OCT4) overexpression restored phosphorylated STAT3-MCL1-mediated apoptosis induced by PHF20 inhibition. In vivo experiments
\end{abstract}

Correspondence to: Dr Wei Xu, Department of Otorhinolaryngology, Head and Neck Surgery, Shandong Provincial ENT Hospital, Cheeloo College of Medicine, Shandong University, 4 West Duanxing Road, Jinan, Shandong 250012, P.R. China

E-mail: xuwhns@126.com

*Contributed equally

Abbreviations: HSCC, hypopharyngeal squamous cell carcinoma; Cis, cisplatin; Bcl-2, B-cell lymphoma 2; MCL1, myeloid cell leukemia-1; PHF20, plant homeodomain finger protein 20

Key words: plant homeodomain finger protein 20, apoptosis, cisplatin resistance confirmed that PHF20 silencing induced tumor growth and increased apoptosis in HSCC cells compared with those in the control cells. Thus, PHF20 inhibition may promote apoptosis and improve cisplatin chemosensitivity via the OCT4-p-STAT3-MCL1 signaling pathway in HSCC.

\section{Introduction}

Hypopharyngeal squamous cell carcinoma (HSCC) is one of the most aggressive types of head and neck cancer; $70-85 \%$ of patients with HSCC are diagnosed at stage III or IV, and the 5 -year overall survival rates are $15-45 \%$ based on studies in the USA and Australia between 1971 and 2002 (1-3). In addition to surgery, adjuvant chemotherapy is commonly used in the multidisciplinary treatment of HSCC. Cisplatin is the most widely used platinum-based chemotherapeutic agent for solid tumors, such as HSCC (4). However, resistance to cisplatin limits its clinical efficiency and the improvement of survival rate in patients with HSCC (5).

The anticancer mechanism of cisplatin involves the activation of DNA damage response and intrinsic apoptosis (6). Intrinsic apoptosis involves apoptotic executioners including caspase-3, which cleave substrates such as poly(ADP-ribose) polymerase 1 (PARP1), resulting in morphological and biochemical alterations (7). In addition, cisplatin-induced apoptosis is regulated by the B-cell lymphoma 2 (Bcl-2) protein family, which serves as an apoptotic switch (8). The Bcl-2 protein family includes pro-apoptotic and anti-apoptotic proteins, such as myeloid cell leukemia-1 (MCL1), which regulates the intrinsic apoptosis pathway (9). Various MCL1 inhibitors have been developed, providing effective approaches for the chemosensitization of esophageal squamous carcinoma cells to cisplatin (10). Thus, understanding the detailed molecular mechanisms through which cisplatin chemoresistance is developed may help in the development of effective treatments against HSCC.

Plant homeodomain finger protein 20 (PHF20), also termed glioma-expressed antigen 2 , is a potent transcriptional activator (11). PHF20 expression is associated with 
tumorigenesis (12). PHF20 expression is also associated with a good prognosis of non-small-cell lung cancer, and PHF20 activates NF- $\kappa$ B at the transcriptional factor (13). However, PHF20 is highly expressed in neuroblastoma and promotes the aggressiveness of neuroblastoma cells by directly binding to the promotor regions of octamer-binding transcription factor 4 (OCT4) (14). OCT4 is a key nuclear transcriptional factor that maintains the pluripotency and self-renewal properties of embryonic stem cells (15). OCT4 affects the tumorigenesis of a number of types of cancer including pancreatic, cervical and ovarian cancer, as well as glioma (16-18). OCT4 inhibits apoptosis in cervical cancer by inhibiting microRNA-125b expression (19), whereas its knockdown suppresses the viability and mobility of hepatocellular carcinoma cells and is associated with low expression levels of survivin and phosphorylated STAT3 (20). Furthermore, OCT4 expression promotes the differentiation of lung cancer cells into small lung cancer cells and acquisition of drug resistance $(21,22)$, and its knockdown sensitizes cancer cells to cisplatin treatment in bladder and non-small lung cancer cells $(23,24)$. Thus, the present study aimed to determine whether the expression of PHF20 may be associated with apoptosis and cisplatin resistance in HSCC cells.

A previous study has demonstrated that PHF20 is involved in tumorigenesis (25). However, the expression level and role of PHF20 in apoptosis and cisplatin sensitivity remain unclear. The aim of the present study was to determine the expression levels of PHF20 in cisplatin-resistant and cisplatin-sensitive HSCC cells and to investigate whether PHF20 knockdown induced apoptosis and sensitized HSCC cells to cisplatin treatment. These results may indicate whether PHF20 may be used as a potential therapeutic target in HSCC to improve cisplatin sensitivity.

\section{Materials and methods}

Cell lines and culture. The FaDu cell line was used as the HSCC model and was obtained from the American Type Culture Collection. FaDu cells were cultured in DMEM/F12 (1:1; Gibco; Thermo Fisher Scientific, Inc.) supplemented with $10 \%$ fetal bovine serum (FBS; Biological Industries). The cells were incubated at $37^{\circ} \mathrm{C}$ in a humidified incubator with $5 \% \mathrm{CO}_{2}$. Cisplatin was obtained from Sigma-Aldrich; Merck KGaA (cat. no. P4394) and dissolved in $0.9 \%$ sodium chloride solution to obtain a $2-\mu \mathrm{M}$ stock solution.

Establishment of a cisplatin-resistant HSCC cell line. First, FaDu cells were treated with various concentrations $(0,1,2,4$, $8,16$ and $32 \mu \mathrm{M})$ of cisplatin for 2 days, and the half maximal inhibitory concentration $\left(\mathrm{IC}_{50}\right.$ ) was determined. FaDu cells were subsequently treated with the culture medium containing $0.25 \mu \mathrm{M}$ cisplatin for $48 \mathrm{~h}$. The solution was discarded, and the cells were recovered for $72 \mathrm{~h}$ in fresh medium without cisplatin. The concentrations of cisplatin were gradually increased $\sim 1$ month later, and cisplatin-resistant FaDu cells were generated for $\sim 6$ months.

RNA sequencing. To analyze the genes with altered expression levels in FaDu cells due to cisplatin resistance, total RNA was isolated from the cells using the Direct-Zol ${ }^{\text {TM }}$ RNA MiniPep kit (cat. no. R2052; Zymo Research Corp.). The experiments were performed in triplicate. Total RNA was qualified and quantified using a NanoDrop 2000 and Agilent 2100 Bioanalyzer (Thermo Fisher Scientific, Inc.). cDNA was generated according to the manufacturer's instructions. The single-stranded circular DNA was formatted as the final library, which was amplified to produce a DNA nanoball (DNB) and loaded into the patterned nanoarray, and single-end 50-base reads were generated on the MGISEQ2000 platform. The concentration of the final library was detected by Nanodrop 2000. The final library was pooled in equimolar concentrations ( 9.4 nM) and sequenced on the MGISEQ2000 platform. CoolMPS high-through sequencing kit (cat. no. 1000018234; MGISEQ-2000RS FCL SE50; BGI Group) was used to determine the sequences of the libraries. Differential expression analysis was performed using the DEGseq ${ }^{2}$ package with $\mathrm{R}$ software (3.6.3) $(26,27)$. Fold-change $>2$ and $\mathrm{P}<0.001$ were used as the screening criteria.

Cell viability assay. Cell viability was detected using the Cell Counting Kit-8 (CCK-8) assay (Beyotime Institute of Biotechnology). A total of $\sim 4 \times 10^{3}$ cells were seeded in each well of 96-well plates containing $100 \mu \mathrm{l}$ medium. A total of $10 \mu \mathrm{l}$ of CCK-8 solution was added to each well at 24,48 , 72 or $96 \mathrm{~h}$ after cell seeding and incubated for $2 \mathrm{~h}$ at $37^{\circ} \mathrm{C}$. Subsequently, optical density was measured at $450 \mathrm{~nm}$ to determine the cell viability by using a microplate reader (BioTek Instruments, Inc.).

$R N A$ extraction and reverse transcription-quantitative $P C R$ (RT-qPCR). Total RNA was extracted from cells using TRIzol $^{\circledR}$ reagent (Thermo Fisher Scientific, Inc.) according to the manufacturer's instructions. cDNAs were synthesized using the RevertAid ${ }^{\mathrm{TM}}$ First Strand cDNA synthesis kit (Thermo Fisher Scientific, Inc.) as follows: The reaction mixture was prepared, the samples were incubated for $60 \mathrm{~min}$ at $42^{\circ} \mathrm{C}$, following which the reaction was terminated for 5 min at $70^{\circ} \mathrm{C}$. qPCR was performed using $\mathrm{SYBR}^{\circledR}$ Premix Ex Taq (Promega Corporation) on Mastercycler ${ }^{\circledR}$ RealPlex 2 (Eppendorf) under the following conditions: $95^{\circ} \mathrm{C}$ for $2 \mathrm{~min}$, followed by 40 cycles of $95^{\circ} \mathrm{C}$ for $20 \mathrm{sec}, 58^{\circ} \mathrm{C}$ for $20 \mathrm{sec}$ and $72^{\circ} \mathrm{C}$ for $20 \mathrm{sec}$, and a final dissolution curve. The primer sequences were as follows: PHF20 forward, 5'-GAATGGTCA ATGCGAGTGG-3' and reverse, 5'-TGGCAGCAAGGCTAC TGTG-3'; OCT4 forward, 5'-TTGCCGCAAAGTGTGTAA CG-3' and reverse, 5'-GTCACCCCTAAATGCCACCG-3'; OCT4A forward, 5'-CGTGAAGCTGGAGAAGGAGAAGCT G-3' and reverse, 5'-CAAGGGCCGCAGCTTACACATGTT C-3'; OCT4B forward, 5'-ATGCATGAGTCAGTGAACAG-3' and reverse, 5'-CCACATCGGCCTGTGTATAT-3'; OCT4B1 forward, 5'-GGGTTCTATTTGGTGGGTTCC-3' and reverse, 5'-TCССТСТСССТАСТССТСТТСА-3'; and $\beta$-actin forward, 5'-CCAACCGCGAGAAGATGA-3' and reverse, 5'-CCAGAG GCGTACAGGGATAG-3'. Data were analyzed using the $2^{-\Delta \Delta \mathrm{Cq}}$ method (28).

Western blotting. The target cisplatin-sensitive, -resistant and transfected FaDu cells were washed with ice-cold phosphate-buffered saline (PBS), lysed with RIPA lysis buffer (cat. no. P0013B; Beyotime Institute of Biotechnology) 
containing phosphatase (cat. no. 04906837001; Roche Applied Science) and protease inhibitors (cat. no. 04693159001; Roche Applied Science), and centrifuged at 12,000 x g for $15 \mathrm{~min}$ at $4^{\circ} \mathrm{C}$. The supernatant was collected, and the protein concentration was measured by BCA assay (Beyotime Institute of Biotechnology). Protein lysates (30 $\mu \mathrm{g} /$ lane) were separated via $10 \%$ SDS-PAGE and transferred to polyvinylidene difluoride membranes (MilliporeSigma). The membranes were blocked with $5 \%$ non-fat milk for $1 \mathrm{~h}$ at room temperature, followed by incubation with primary antibodies at $4^{\circ} \mathrm{C}$ overnight. The following primary antibodies were used: PHF20 (1:2,000; cat. no. 3934S; Cell Signaling Technology, Inc.), phosphorylated (p)-STAT3 (1:1,000; cat. no. 9131S; Cell Signaling Technology, Inc.), OCT4 (1:1,000; cat. no. 2750S; Cell Signaling Technology, Inc.), MCL1 (1:1,000; cat. no. sc-12756; Santa Cruz Biotechnology, Inc.), PARP1 (1:1,000; cat. no. 9562S; Cell Signaling Technology, Inc.), caspase-3 (1:1,000; cat. no. 9662S; Cell Signaling Technology, Inc.), STAT3 (1:20,000; cat. no. 610189; BD Biosciences), OCT4A (1:1,000; cat. no. C52G3; Cell Signaling Technology, Inc.), OCT4B1 (1:4,000; cat. no. bs-3816R; Bioss) and $\beta$-actin (1:40,000; cat. no. TA-09; OriGene Technologies, Inc.). After washing three times in phosphate buffered saline with $0.05 \%$ Tween-20, the membranes were incubated at room temperature for $1 \mathrm{~h}$ with horseradish peroxidase-conjugated secondary antibodies (1:20,000; goat anti-mouse IgG; cat. no. ZB-5305; goat anti-rabbit IgG; cat. no. ZB-5301; OriGene Technologies, Inc.). An enhanced chemiluminescence reagent (cat. no. WBKLS0500; MilliporeSigma) was used to visualize the target bands, and the protein densities were quantified using ImageJ software (version 1.37; National Institutes of Health).

5-Ethynyl-2'-deoxyuridine (EDU) labeling assay. In vitro cell proliferation was assessed using the kFluor647-EdU imaging kit (Nanjing KeyGen Biotech Co., Ltd.) according to the manufacturer's instructions. The proportion of cells that incorporated EDU $\left(\mathrm{EDU}^{+}\right)$was determined using a fluorescence microscope (Leica Microsystems $\mathrm{GmbH}$ ) in $\geq 3$ randomly selected fields (x63 magnification) per sample.

Lentivirus-based short hairpin RNA (shRNA) infection. Lentivirus vector GV493-green fluorescent protein (GFP) containing scramble shRNA (Scr) or shRNA targeting PHF20 (shPHF) were obtained from Shanghai Genechem Co., Ltd. The target sequence was 5'-CCAGCTCACATAGAAGAC ATT-3'. A random Scr sequence, 5'-GTTCTCCGAACGTGT CACGT-3', was used as a negative control. FaDu cells were seeded in 6-well plates at the density of $1 \times 10^{5} / \mathrm{ml}$ for $24 \mathrm{~h}$, and were infected with shPHF20 or Scr (MOI=10) for $16 \mathrm{~h}$ at $37^{\circ} \mathrm{C}$. Subsequently, puromycin (cat. no. A610593-0025; Sangon) was added to the culture medium at $37^{\circ} \mathrm{C}$ with $5 \% \mathrm{CO}_{2}$ for $\sim 14$ days according to the manufacturer's instructions to generate stable FaDu PHF20-knockdown cell lines. The lentiviral infection efficiency was determined by fluorescence microscopy and western blot assay.

Migration and invasion assays. Transwell assays were performed to detect the target cell migration and invasion. FaDu cells were harvested during the logarithmic growth phase, washed with PBS and suspended in DMEM without FBS at $4 \times 10^{5}$ cells $/ \mathrm{ml}$. The upper chamber of the Transwell inset (Costar; Corning, Inc.) was filled with $250 \mu \mathrm{l}$ of cell suspension, and the lower chamber was filled with $700 \mu \mathrm{l}$ DMEM/F-12 with $20 \%$ FBS as a chemoattractant. The cells were incubated for $24 \mathrm{~h}$ at $37^{\circ} \mathrm{C}$. The non-migrating cells were removed by a cotton swab, and the migratory cells were fixed with $4 \%$ formaldehyde at room temperature for $15 \mathrm{~min}$ and stained with $0.1 \%$ crystal violet at room temperature for $25 \mathrm{~min}$. The stained cells were counted in five random fields per sample under a light microscope (magnification, x100). Transwell chambers precoated with Matrigel (BD Biosciences) for $30 \mathrm{~min}$ at $37^{\circ} \mathrm{C}$ were used for cell invasion assays following a similar protocol as the cell migration assays, with the exception that the cells were incubated for $36 \mathrm{~h}$ due to the Matrigel barrier. The experiments were repeated at least thrice.

Immunofluorescence (IF) assay. FaDu cells were cultured on glass coverslips and fixed with $4 \%$ paraformaldehyde at room temperature for $20 \mathrm{~min}$, washed with cold PBS and permeabilized with $0.2 \%$ Triton $\mathrm{X}-100$ for $10 \mathrm{~min}$ to rupture the cell membranes. Non-specific antigen-binding sites were blocked by $1 \%$ bovine serum albumin (Beijing Solarbio Science \& Technology Co., Ltd.) in PBS for $1 \mathrm{~h}$ at room temperature. After washing with PBS, the cells were incubated with anti-PHF20 (1:200; cat. no. ab67796; Abcam), anti-STAT3 (1:50; cat. no.9139; Cell Signaling Technology, Inc.) and anti-p-STAT3 (1:200; cat. no. 9145S; Cell Signaling Technology, Inc.) overnight at $4^{\circ} \mathrm{C}$. Following washing thrice with PBS, the cells were incubated with a DyLight ${ }^{\circledR}$ 546-cojugated donkey anti-rabbit secondary antibody for PHF20 and p-STAT3 (1:1,000; cat. no. A10040) and a fluorescein-conjugated goat anti-mouse secondary antibody for STAT3 (1:1,000, F2761) (both Invitrogen; Thermo Fisher Scientific, Inc.) for $1 \mathrm{~h}$ at room temperature. Cells were washed twice with PBS, and the nuclei were stained with 4',6-diamidino-2-phenylindole (Sigma-Aldrich; Merck KGaA) for $15 \mathrm{~min}$ at room temperature. Cells were observed five random fields (x63 magnification) under a TCS SPE confocal microscope (Leica Microsystems $\mathrm{GmbH}$ ).

Tumor xenografts in nude mice. Male BALB/c nude mice (age, 4 weeks) were obtained from Charles River Laboratories via Beijing Vital River Laboratory Animal Technology Co., Ltd. and maintained in a temperature- and humidity-controlled environment $\left(22 \pm 1^{\circ} \mathrm{C}\right.$; $40-60 \%$ humidity) with a $12: 12 \mathrm{~h}$ light-dark cycle and free access to food and water. The study was performed with the approval from the Committee for the Animal Care and Use of Shandong Provincial ENT Hospital. The mice were randomly divided into two groups $(n=6$ per group). shPHF or Scr cells ( $1 \times 10^{6}$ cells/mouse) were subcutaneously injected into the left dorsal flank. The length and width of the tumors were examined every 2 days using digital calipers. On day 23 post-inoculation, the mice were sacrificed by carbon dioxide asphyxiation (20\% chamber volume/min), and the tumors were excised, fixed with $4 \%$ paraformaldehyde for $24 \mathrm{~h}$ at room temperature and embedded in paraffin for hematoxylin and eosin (H\&E) and immunohistochemistry (IHC) staining.

$H \& E$ and IHC staining. The paraffin-embedded tumor tissues from mice were cut into $2-\mu \mathrm{m}$ sections and routinely stained 
with H\&E for histological diagnosis. The tissue sections were de-paraffinized and rehydrated, and the tissue antigen was retrieved using target retrieval solution (OriGene Technologies, Inc.) according to the manufacturer's protocol. The slides were washed with PBS and incubated with the anti-PHF20 polyclonal (1:200; cat. no. 124224; Abcam), anti-p-STAT3 (1:200; cat. no. 9145S; Cell Signaling Technology, Inc.) and anti-Ki67 (diluted 1:200; cat. no. ZA-0502; OriGene Technologies, Inc.) primary antibodies at $4^{\circ} \mathrm{C}$ overnight. After washing thrice with PBS, the sections were incubated with secondary biotinylated goat anti-rabbit IgG antibody (1:500, cat. no. SP-9001; OriGene Technologies, Inc.) for $15 \mathrm{~min}$. The tissue sections were examined, and images were captured using Olympus BX53 microscope (Olympus Corporation) in five random fields per sample (x200 magnification).

Flow cytometry. To determine the cell cycle phase, FaDu cells were harvested at the logarithmic growth phase and washed twice with ice-cold PBS. The cell density was adjusted to $1 \times 10^{6}$ cells $/ \mathrm{ml}$, and the cells were fixed with $70 \%$ ethanol at $4^{\circ} \mathrm{C}$ overnight. The cells were stained with propidium iodide $(10 \mu \mathrm{g} / \mathrm{ml}$; Sigma-Aldrich; Merck KGaA) in the presence of RNase $(10 \mu \mathrm{g} / \mathrm{ml}$; Tiangen Biotech Co., Ltd.) for $\leq 30 \mathrm{~min}$. Subsequently, the cells were harvested and analyzed by a FACSCalibur flow cytometer (BD Biosciences) to detect the cell cycle phase. The fluorescent signal was detected through the FL2 channel, and the proportion of DNA in different phases was analyzed using ModfitLT Version 3.3.11 (Verity Software House, Inc.).

Apoptotic cells were detected using the Annexin Vphycoerythrin (PE)/7-aminoactinomycin D (7-ADD) apoptosis detection kit (Nanjing KeyGen Biotech Co., Ltd.) by flow cytometry. Briefly, $1 \times 10^{6} \mathrm{FaDu}$ cells were treated with $2 \mu \mathrm{M}$ cisplatin for $48 \mathrm{~h}$, harvested, washed and resuspended in $50 \mu \mathrm{l}$ binding buffer containing $5 \mu \mathrm{l}$ 7-ADD at room temperature in the dark for $10 \mathrm{~min}$. Subsequently, the cells were incubated in $500 \mu \mathrm{l}$ binding buffer containing $1 \mu \mathrm{l}$ PE-conjugated Annexin $\mathrm{V}$ at room temperature for $10 \mathrm{~min}$. Annexin V- and 7-ADD-positive apoptotic cells were detected using a FACSCalibur flow cytometer. Annexin V-PE-positive and 7-ADD-negative cells were considered as early apoptotic cells, whereas positivity for both Annexin V and 7-ADD was considered to indicate late apoptosis.

Terminal deoxynucleotidyl transferase-mediated dUTP-biotin nick end labeling (TUNEL) assay. To assess apoptotic cells in tissues, $2-\mu \mathrm{m}$ tumor tissue sections were analyzed by TUNEL assay (in situ Cell Death Detection kit; Roche Applied Sciences). Apoptotic cells (TUNEL ${ }^{+}$) were counted as the percentage of the total cells. TUNEL ${ }^{+}$cells were counted in five random fields per slide, and five slides per group were analyzed by fluorescence microscopy at x400 magnification.

Statistical analysis. All statistical analyses were performed using SPSS 17.0 (SPSS, Inc.). Student's t-test was used to determine significant difference between two groups. Differences among multiple groups were analyzed with mixed model ANOVA followed by the Tukey's post-hoc test. Data were obtained from at $\geq 3$ independent experiments and presented as the mean \pm SEM. $\mathrm{P}<0.05$ was considered to indicate a statistically significant difference.

\section{Results}

PHF2O is upregulated in cisplatin-resistant HSCC cells. To establish a cisplatin-resistant HSCC cell line, FaDu cells were treated with cisplatin, and the $\mathrm{IC}_{50}$ was determined. The $\mathrm{IC}_{50}$ of FaDu cells was $2.370 \mu \mathrm{M}$ with a $95 \%$ confidence interval (CI) of 2.228-2.529 $\mu \mathrm{M}$. The $\mathrm{IC}_{50}$ of cisplatin-resistant FaDu cells was $6.937 \mu \mathrm{M}$ with a $95 \% \mathrm{CI}$ of $6.379-7.543 \mu \mathrm{M}$. To establish a cisplatin-resistance model, $\mathrm{FaDu}$ cells were treated with increasing doses of cisplatin for 6 months. Throughout the selection period, the sensitivity of cells to cisplatin was detected via CCK-8 assay, and a stable cell population resistant to cisplatin $\left(\mathrm{FaDu}_{\mathrm{CIS}-\mathrm{R}}\right)$ was obtained with a resistance index (RI) of 2.927 (Fig. 1A) compared with parental $\mathrm{FaDu}$ cells $\left(\mathrm{FaDu}_{\mathrm{CIS}-\mathrm{S}}\right)$. Cell viability was significantly lower in $\mathrm{FaDu}_{\mathrm{CIS}-\mathrm{S}}+\mathrm{C}$ is cells compared with that in $\mathrm{FaDu}_{\mathrm{CIS}-\mathrm{R}}+\mathrm{Cis}$ cells (Fig. 1B).

To comprehensively survey the genes associated with cisplatin resistance, RNA sequencing was performed in $\mathrm{FaDu}$ cells sensitive and resistant to cisplatin. The sequencing data are available at the Sequence Read Archive database of NCBI (accession nos. SRR13805665, SRR13805664, SRR13805661, SRR13805657, SRR13805656 and SRR13805655). With fold-change $>2$ and $\mathrm{P}<0.001$ used as the screening criteria in gene detection, the transcriptome sequencing analysis identified 24,361 differently expressed genes between $\mathrm{FaDu}_{\mathrm{CIS}-\mathrm{R}}$ and $\mathrm{FaDu}_{\mathrm{CIS}-\mathrm{S}}$, including 14,487 upregulated and 9,874 downregulated genes. Intrinsic apoptosis is one leading mechanisms of cisplatin resistance (29); in the present study, the RNA sequencing results (Table I) demonstrated that MCL1, an apical molecule in apoptosis control and promoting cell survival (30), was also significantly upregulated in $\mathrm{FaDu}_{\mathrm{CIS}-\mathrm{R}}$ compared with $\mathrm{FaDu}_{\text {CIS-S }}$ cells $(\mathrm{P}<0.001$; Table I). In addition, at the protein level, the expression levels of MCL1 increased, whereas the levels of cleaved caspase-3 and PARP1 decreased in FaDu $\mathrm{CIS}_{\mathrm{C}}$ cells compared with those in $\mathrm{FaDu}_{\mathrm{CIS}-\mathrm{S}}$ cells under cisplatin treatment, indicating apoptosis (Fig. 1C and D).

Among the differentially regulated genes between the two cell types analyzed in the present study, PHF20 was remarkably upregulated in $\mathrm{FaDu}_{\mathrm{CIS}-\mathrm{R}}$ cells $(\mathrm{P}<0.001$; Table I). The expression levels of PHF20 were validated by RT-qPCR and western blotting. $\mathrm{FaDu}_{\mathrm{CIS}-\mathrm{R}}$ cells exhibited higher expression levels of PHF20 compared with those in $\mathrm{FaDu}_{\mathrm{CIS}-\mathrm{S}}$ cells (Fig. 1C-E), suggesting the accumulation of PHF20 in chemoresistant HSCC cells. These results suggested the PHF20 expression may be associated with apoptosis and chemoresistance in HSCC cells.

Inhibition of PHF2O suppresses HSCC cell viability by promoting apoptosis in vitro. The increased levels of PHF20 were associated with cisplatin resistance. The anticancer mechanism of cisplatin involves the activation of DNA damage response and intrinsic mitochondrial apoptosis (6). Therefore, the present study further investigated the effects of PHF20 on the biological phenotype of HSCC cells. CCK-8, migration, and invasion assays were performed in $\mathrm{FaDu}$ cells following PHF20 inhibition. Stable PHF20-knockdown FaDu cell lines were established by lentivirus infection. The protein and mRNA expression levels of PHF20 were significantly inhibited in FaDu cells following PHF20 knockdown compared with those in the control cells (Fig. 2A-C). PHF20 
A

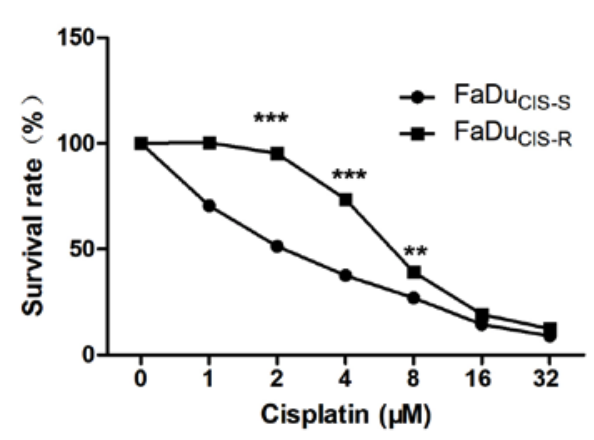

C

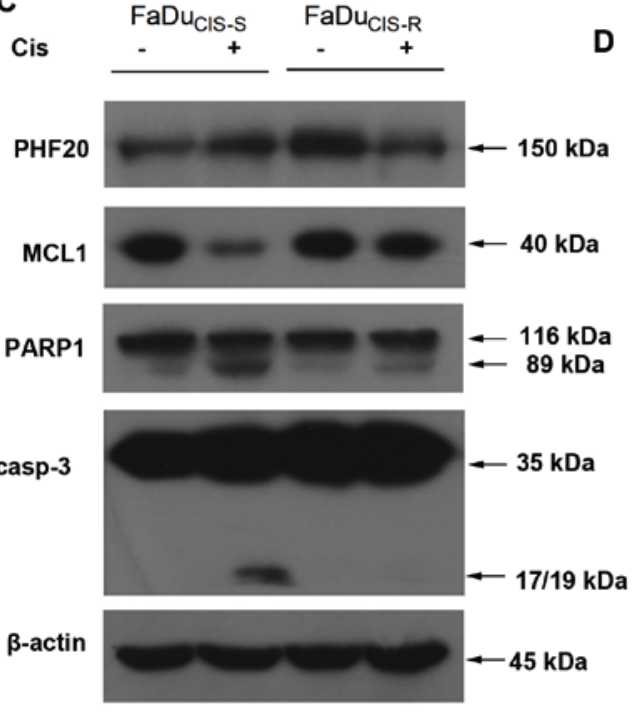

B
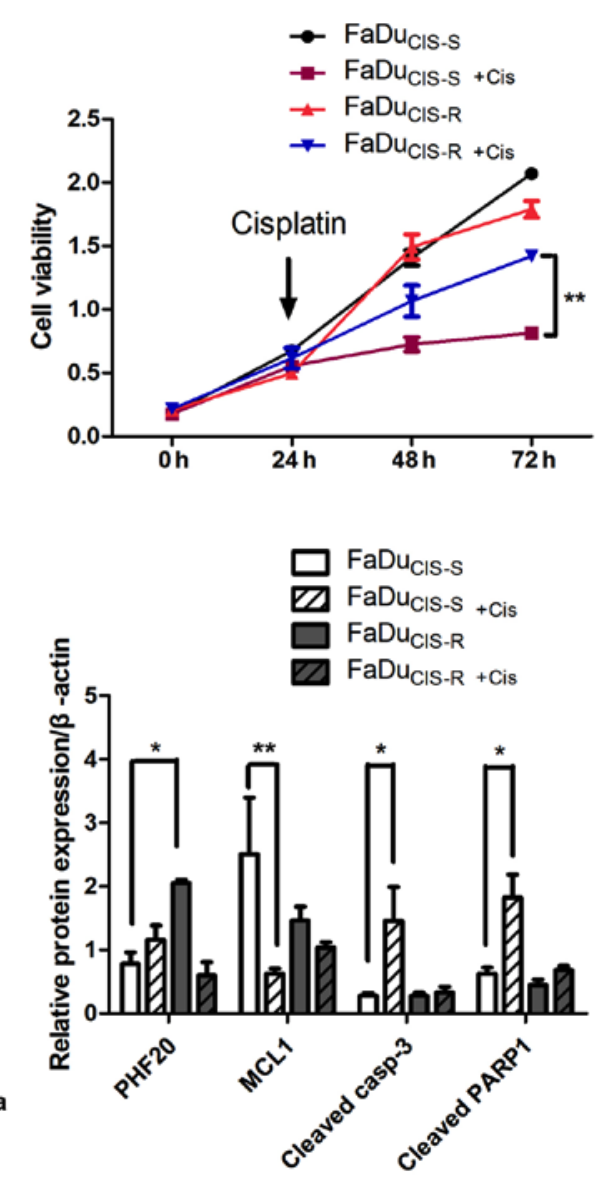

E

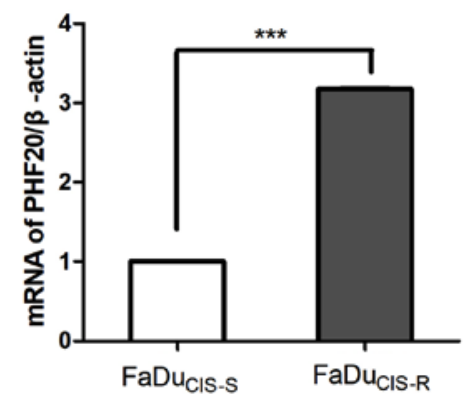

Figure 1. PHF20 is upregulated in cisplatin-resistant HSCC cells. (A) The survival rate of cisplatin-sensitive and resistant HSCC cells following cisplatin treatment was determined using the Cell Counting Kit-8 assay. (B) The viability of FaDu $\mathrm{CIS-}_{\mathrm{R}}$ and $\mathrm{FaDu}_{\mathrm{CIS}-\mathrm{s}}$ cells was determined using the Cell Counting Kit-8 assay. Mixed model ANOVA was used for analysis. (C) Western blot analysis was used to detect the expression levels of apoptosis-related molecules MCL1, caspase-3 and PARP1 in FaDu $\mathrm{CIS}-\mathrm{R}_{\mathrm{R}}$ and $\mathrm{FaDu}_{\mathrm{CIS}-\mathrm{S}}$ cells treated with or without cisplatin. $\beta$-actin was used as an internal reference. (D) Quantitative analysis of the western blotting data. Mixed model ANOVA was used for analysis. (E) Reverse transcription-quantitative PCR revealed that the relative mRNA expression levels of PHF20 significantly increased in $\mathrm{FaDu}_{\text {CIS-R }}$ cells compared with those in $\mathrm{FaDu}_{\text {CIS-s }}$ cells. ${ }^{*} \mathrm{P}<0.05,{ }^{* * *} \mathrm{P}<0.01$ and ${ }^{* * * *} \mathrm{P}<0.001$ vs. FaDu ${ }_{\text {CIs-s }}$ or as indicated. All experiments were performed thrice. Data are presented as the mean \pm SEM. HSCC, hypopharyngeal squamous cell carcinoma; PHF20, plant homeodomain finger protein 20; PARP1, poly(ADP-ribose) polymerase 1; MCL1, myeloid cell leukemia-1.

knockdown significantly decreased the viability (Fig. 2D) but did not affect the migratory (Fig. 2E and F) and invasive (Fig. $2 \mathrm{G}$ and $\mathrm{H}$ ) abilities of FaDu cells compared with those in the Scr group. In addition, the present study examined whether proliferation and/or apoptosis accounted for the decrease in the cell viability of FaDu cells following PHF20 knockdown. No notable differences were observed in the cell proliferative ability as indicated by $\mathrm{EDU}^{+}$and $\mathrm{Ki}^{+} 7^{+}$cells between the two groups (Fig. 3A-D). The cell cycle phase detection by flow cytometry revealed that PHF20 knockdown did not affect the G0/G1 phase and S phase arrest in HSCC cells (Fig. 3E and F).

Western blotting and flow cytometry were used to further investigate whether the PHF20 knockdown-mediated decrease in the cell viability of $\mathrm{FaDu}$ cells was associated with apoptosis. Compared with those in the control cells, the levels of cleaved PARP1 increased in shPHF-transfected cells (Fig. 4A and B). The expression levels of MCL1 were markedly downregulated in shPHF20 cells compared with 

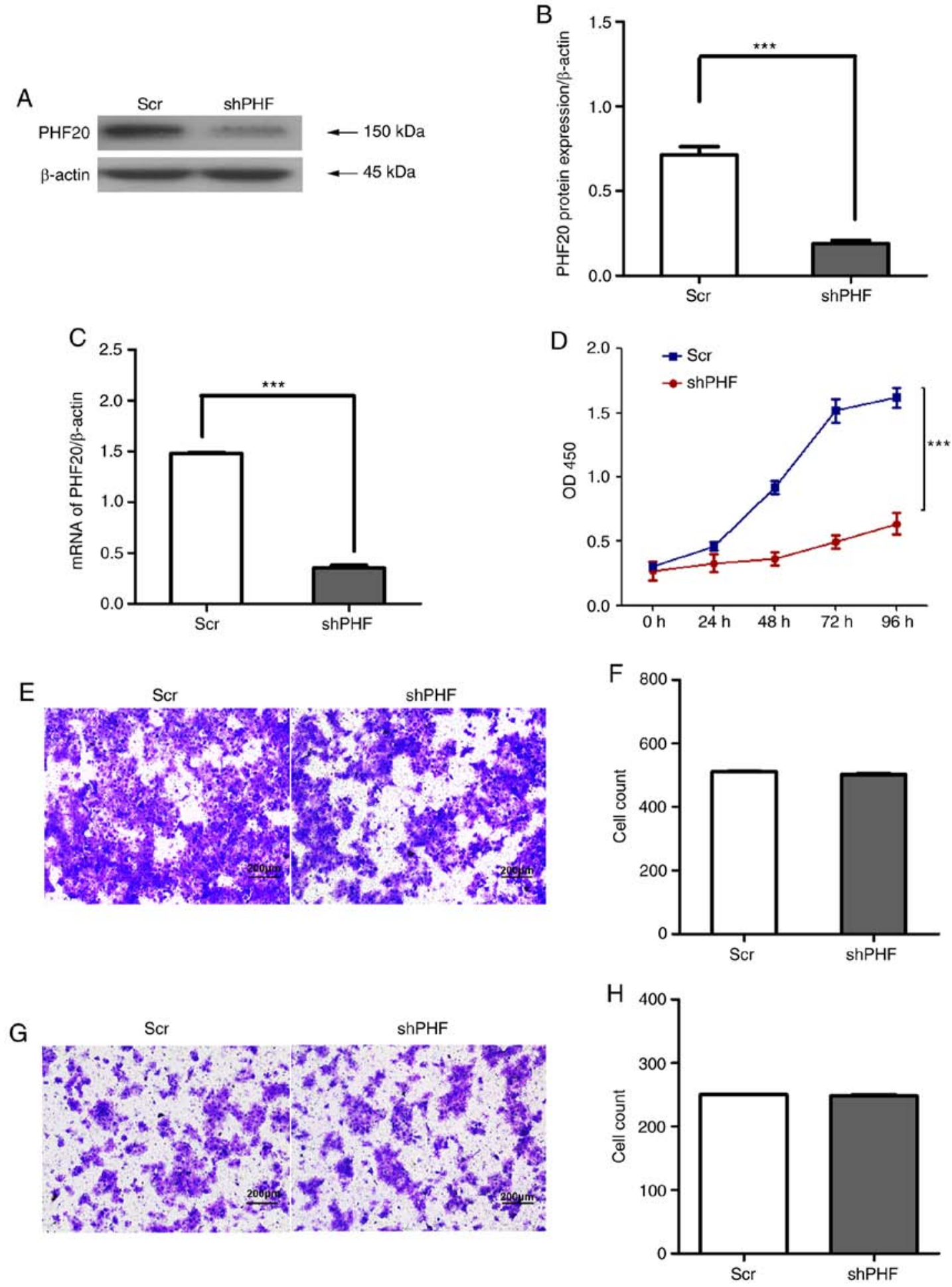

Figure 2. PHF20 inhibition suppresses the viability of FaDu cells. (A) The protein expression levels of PHF20 were detected in shPHF and Scr cells by western blot assay. (B) Quantification of the western blotting results in A. (C) The mRNA expression levels of PHF20 were detected in shPHF- and Scr-transfected cells by reverse transcription-quantitative PCR. (D) The viability of cisplatin-sensitive and resistant FaDu cells was detected using the Cell Counting Kit-8 assay. (E) The migration assay demonstrated no significant differences in the cell numbers between the shPHF and Scr groups. Magnification, x100. Scale bar, $200 \mu \mathrm{m}$. (F) Quantitative analysis of the migratory cells in E. (G) The Invasion assay results were similar to those of the cell migration assay. Magnification, x100. Scale bar, $200 \mu \mathrm{m}$. (H) Quantitative analysis of the invasive cells in G. The experiments were performed in triplicate, and unpaired t-test was used for analysis. ${ }^{* * * *} \mathrm{P}<0.001$. PHF20, plant homeodomain finger protein 20; shPHF, shRNA targeting PHF20; Scr, scramble shRNA.

those in Scr cells (Fig. 4A and B). In addition, PHF20 knockdown significantly increased the apoptotic rate compared with that in the Scr cells, as assessed by flow cytometry with Annexin V (Fig. 4C and D). Therefore, PHF20 knockdown inhibited cell viability by enhancing apoptosis in vitro.
Knockdown of PHF2O improves cisplatin sensitivity in HSCC cells. The upregulation of PHF20 was associated with cisplatin resistance in $\mathrm{FaDu}$ cells. Thus, the present study further examined the effects of PHF20 on the response of FaDu cells to cisplatin treatment $(\mathrm{Scr}, \mathrm{Scr}+\mathrm{Cis}, \mathrm{shPHF}$ and shPHF + 
A
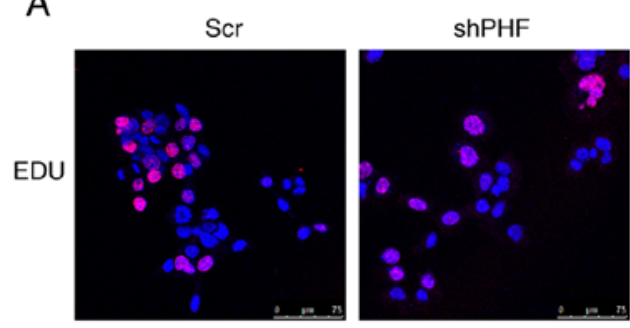

C

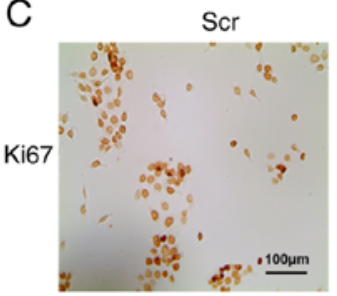

E

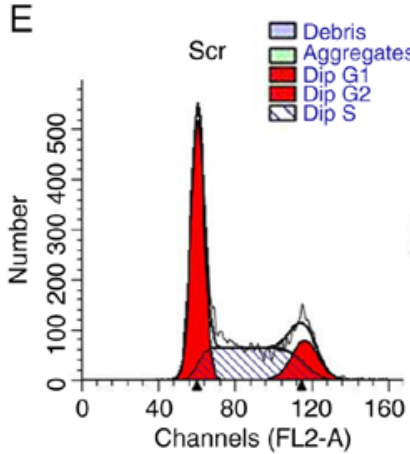

B

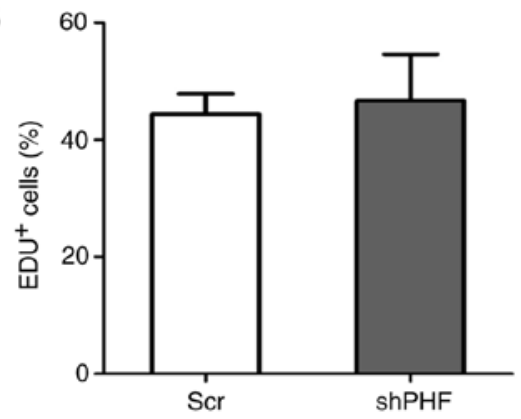

D
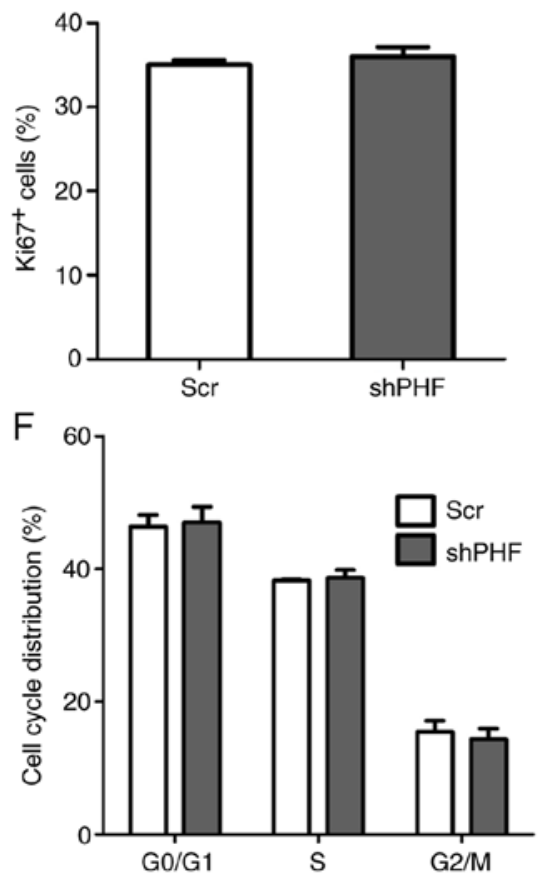

Figure 3. Similar proliferative abilities in shPHF- and Scr-transfected FaDu cells. (A) EDU labeling assay demonstrated that the proliferative ability of FaDu cells was not notably altered following PHF20 knockdown. Scale bar, $75 \mu \mathrm{m}$. (B) Quantitative analysis of EDU+ FaDu cells in A. (C) IHC staining of Ki67 indicated the absence of any significant effects on the proliferation of FaDu cells following PHF20 knockdown compared with that in the control group. Scale bar, $100 \mu \mathrm{m}$. (D) Quantitative analysis of Ki67 ${ }^{+}$FaDu cells in C. (E) Flow cytometry data demonstrated no differences between the cell cycle distribution in shPHF- and Scr-transfected cells. (F) Quantitative analysis of the cell cycle phase distribution in the shPHF and Scr groups. The experiments were performed in triplicate, and unpaired t-test was used for analysis. PHF20, plant homeodomain finger protein 20; shPHF, lentivirus-mediated shRNA targeting PHF20; Scr, scramble shRNA; IHC, immunohistochemistry; EDU, 5-ethynyl-2'-deoxyuridine.

Cis cells). The cell viability was significantly inhibited in the shPHF + Cis group compared with that in the Scr + Cis or shPHF group (Fig. 5A). Western blot analysis results confirmed that the expression levels of MCL1 were downregulated, whereas the levels of cleaved PARP1 and caspase 3 were upregulated in shPHF + Cis cells compared with those in the Scr + Cis and shPHF groups (Fig. 5B and C). Similarly, the flow cytometry results revealed an increased number of apoptotic cells in the shPHF + Cis group compared with those in the Scr + Cis and shPHF groups (Fig. 5D and E). Thus, PHF20 knockdown sensitized HSCC cells to cisplatin-induced apoptosis and effectively suppressed their viability.

PHF20 regulates apoptosis and improves cisplatin sensitivity via the OCT4-p-STAT3-MCL1 signaling pathway. PHF20, as a transcriptional factor, directly binds to the promoter region of the OCT4 gene (31), and its downregulation promotes apoptosis (32). The present study further examined whether OCT4 overexpression in FaDu cells reversed MCL1-mediated apoptosis caused by PHF20 inhibition. The mRNA the expression levels of OCT4 were lower in the shPHF cells compared with those in Scr cells (Fig. 6A). When PHF20 was knocked down, the levels of OCT4, p-STAT3 and MCL1 were downregulated in FaDu cells compared with those in the control group (Fig. 6B and C). In addition, IF assay results demonstrated that PHF20 knockdown decreased the levels and nuclear localization of p-STAT3 in FaDu cells compared with those in Scr cells (Fig. 6D and E). Using co-transfection, OCT4 was overexpressed, while PHF20 was knocked down in FaDu cells; the results demonstrated that OCT4 overexpression restored the reduction in the levels of p-STAT3, MCL1 and cleaved PARP1 repressed by PHF20 knockdown (Fig. 7A and B). Thus, PHF20 knockdown promoted the apoptosis of HSCC cells via OCT4.

Among OCT4 isoforms, OCT4B1 and OCT4A serve important roles in apoptosis $(25,31,33)$. Therefore, we hypothesized that OCT4B1 and OCT4A rather than other OCT4 isoforms may mediate the apoptosis induced by PHF20 knockdown. The expression levels of OCT4A, OCT4B and 

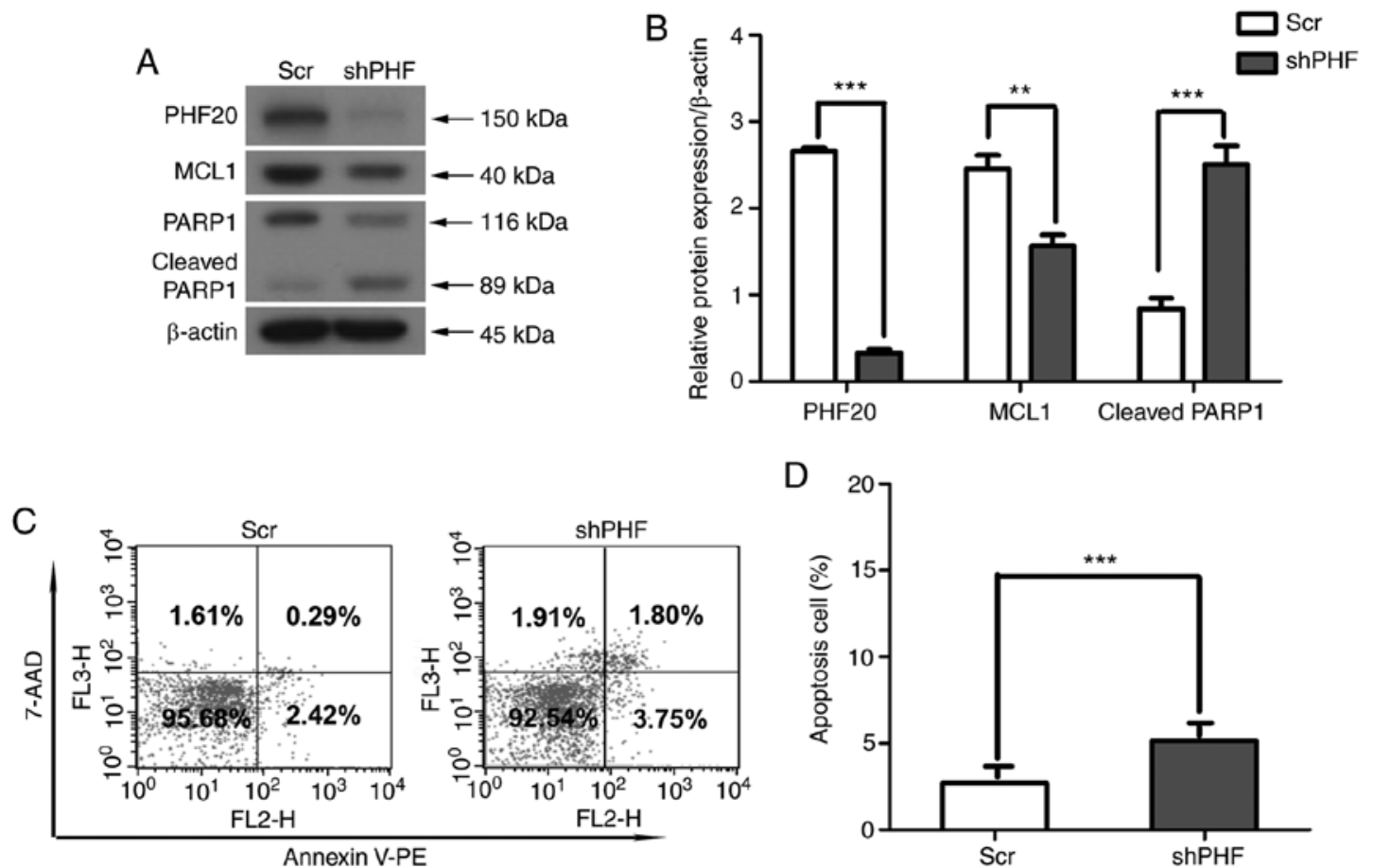

Figure 4. PHF20 inhibition promotes apoptosis in FaDu cells. (A) Western blot assay demonstrated that the expression of MCL1 and cleaved PARP1 decreased in cells with PHF20 knockdown. (B) Quantitative analysis of PHF20, MCL1 and cleaved PARP1 in A. (C) Flow cytometry assay revealed that the proportion of apoptotic cells increased in FaDu cells following PHF20 knockdown compared with that in the control group. (D) Quantitative analysis of apoptotic rates in C. The experiments were performed in triplicate, and unpaired $t$-test was used for analysis. ${ }^{* *} \mathrm{P}<0.01$ and ${ }^{* * *} \mathrm{P}<0.001$. PHF20, plant homeodomain finger protein 20 ; shPHF, lentivirus-mediated shRNA targeting PHF20; Scr, scramble shRNA; PARP1, poly(ADP-ribose) polymerase 1; MCL1, myeloid cell leukemia-1.

OCT4B1 were detected at the transcriptional level, and the results demonstrated that the levels of OCT4A and OCT4B1 were significantly downregulated following PHF20 knockdown compared with those in the Scr group, whereas OCT4B expression was unaffected (Fig. 7C). Western blot analysis results also confirmed the decrease in the protein expression levels of OCT4A and OCT4B1 in the shPHF group compared with those in the Scr group (Fig. 7D and E). These results suggested that in HSCC cells, PHF20 knockdown increases the apoptotic rate via OCT4A and OCT4B1 rather than the other isoforms of OCT4. Therefore, PHF20 knockdown may promote apoptosis by inhibiting the OCT4-p-STAT3-MCL1 signaling pathway in HSCC cells.

PHF20 inhibition suppresses tumorigenicity via apoptosis in a xenograft model of HSCC. To investigate the role of PHF20 in vivo, shPHF and control cells were subcutaneously injected into nude mice in order to establish an animal xenograft model. The tumor appeared at day 7 post-inoculation, and tumor samples were extracted on day 23. As presented in Fig. 8A and B, the tumor volumes were significantly lower, and the tumor growth was notably suppressed in the shPHF group compared with those in the Scr group. Histological analysis and TUNEL assays were performed on the tumor tissue sections from the mice in the two groups. Tumors in the shPHF group exhibited a remarkable decrease in PHF20 levels compared with those in the Scr group (Fig. 8C and D). Consistent with the in vitro results, the number of $\mathrm{Ki}^{+} 7^{+}$cells did not differ significantly in the tumor tissues between the two groups (Fig. 8C and D). Notably, shPHF tumors exhibited a higher number of apoptotic $\mathrm{TUNEL}^{+}$cells, whereas the levels of p-STAT3 decreased compared with those in the Scr group (Fig. 8C and D). Collectively, these results demonstrated that PHF20 knockdown inhibited tumor growth by promoting apoptosis in vivo.

\section{Discussion}

Resistance to cisplatin, a DNA-damaging agent, is a major obstacle for its clinical use in HSCC. In the present study, the levels of PHF20 were upregulated in $\mathrm{FaDu}_{\mathrm{CIS}-\mathrm{R}}$ compared with those in $\mathrm{FaDu}_{\mathrm{CIS}-\mathrm{S}}$ cells, as indicated by RNA sequencing, RT-qPCR and western blotting results. The effects of PHF20 in HSCC and cisplatin sensitivity, as well as the underlying molecular mechanisms, were further investigated. PHF20 knockdown significantly decreased the viability of FaDu cells by accelerating apoptosis, and the tumorigenic role of PHF20 was observed in a mouse xenograft model, where more apoptotic cells were present in the shPHF group compared with the Scr group. PHF20 knockdown sensitized FaDu cells to cisplatin treatment. Notably, cisplatin and PHF20 knockdown synergistically promoted the apoptosis of FaDu cells via the OCT4-p-STAT3-MCL1 signaling pathway. These results suggested a potential underlying mechanism by which knockdown of PHF20 may promote apoptosis in vitro and in vivo and improve cisplatin-based chemosensitivity in HSCC cells. A schematic diagram of the proposed mechanism is presented in Fig. 8E.

PHF20 is an antigen in patients with glioblastoma that is highly expressed in various types of cancer, including non-small cell lung cancer, glioblastoma and nasopharyngeal carcinoma $(12,14)$ and participates in the development and progression of glioma, adenocarcinomas and lung cancer (12). 

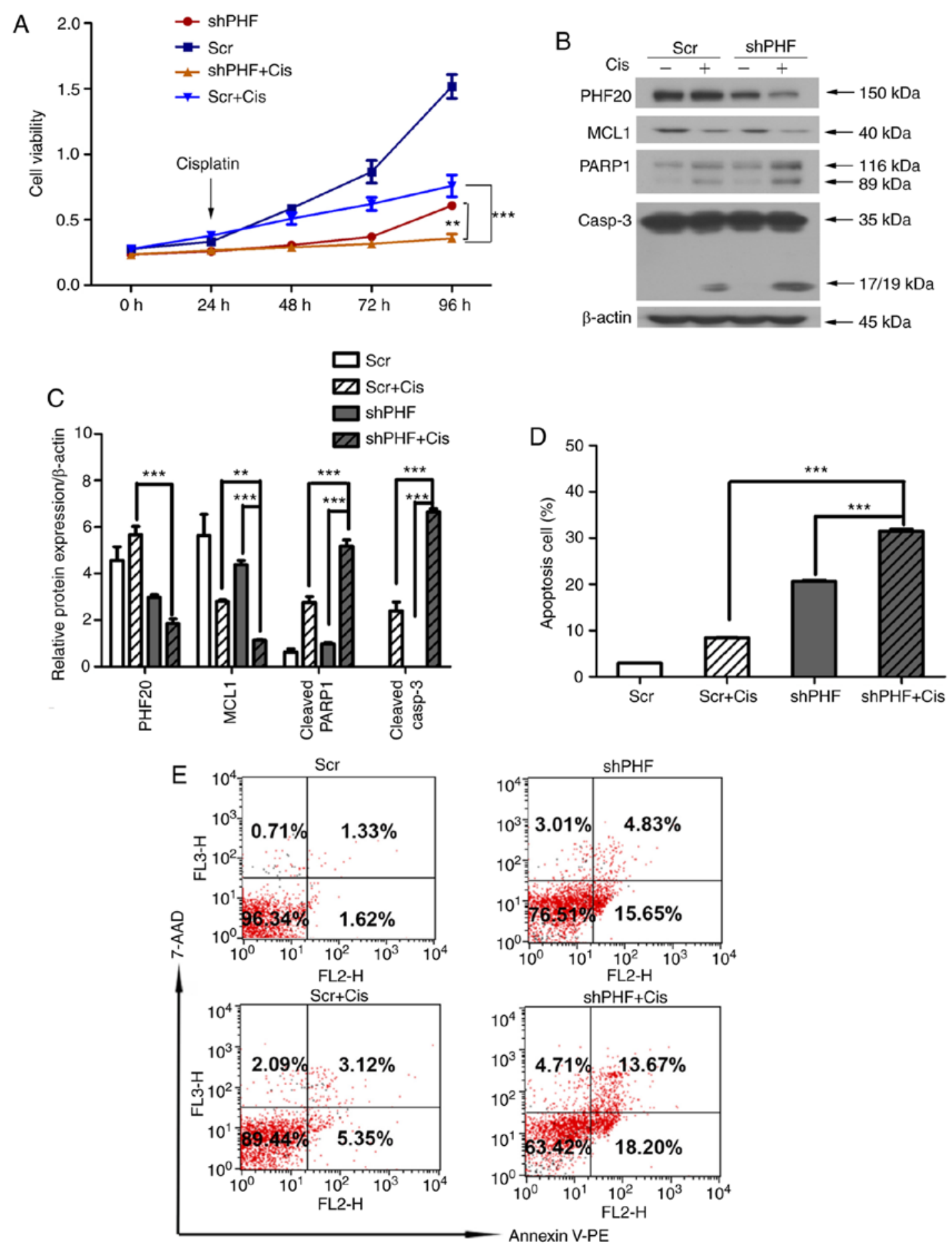

Figure 5. Inhibition of PHF20 improves cisplatin sensitivity in HSCC cells. (A) The cell viability was detected using the Cell Counting Kit-8 assay in shPHF- and Scr-transfected cells treated with or without cisplatin. Compared with those in the shPHF and Scr + Cis groups, the cell viability in the shPHF + Cis group significantly decreased. (B) Western blot assay results demonstrated that the protein expression levels of MCL1 decreased in shPHF cells treated with cisplatin compared with those in the shPHF and Scr + Cis groups, whereas the levels of cleaved PARP1 and caspase-3 increased in the same conditions. (C) Quantitative analysis of the Western blot results in B. (D) Apoptosis was detected by flow cytometry in shPHF- and Scr-transfected cells treated with or without cisplatin. (E) Quantitative analysis of apoptosis in D. The results revealed that the proportion of apoptotic cells was significantly higher in the shPHF + Cis group compared with that in the Scr + Cis and shPHF groups. Mixed model ANOVA was used for analysis. The experiments were performed in triplicate. ${ }^{* *} \mathrm{P}<0.01$ and ${ }^{* * * *} \mathrm{P}<0.001$. PHF20, plant homeodomain finger protein 20; shPHF, lentivirus-mediated shRNA targeting PHF20; Scr, scramble shRNA; PARP1, poly(ADP-ribose) polymerase 1; MCL1, myeloid cell leukemia-1; OD, optical density; casp-3, caspase-3.

$\mathrm{NF}-\kappa \mathrm{B}$, which promotes the development of inflammation-associated cancer, is activated by high expression levels of PHF20 (34). Cui et al (35) have reported that PHF20 stabilizes p53 through dimethylated lysine residues for cell survival and carcinogenic activity. The results of the present study provided valuable information for improved understanding of the role of PHF20 knockdown in regulating apoptosis via the OCT4-p-STAT3-MCL1 signaling pathway in HSCC.

Cisplatin is one of the most potent chemotherapeutic regimens that is widely used for the treatment of various types 

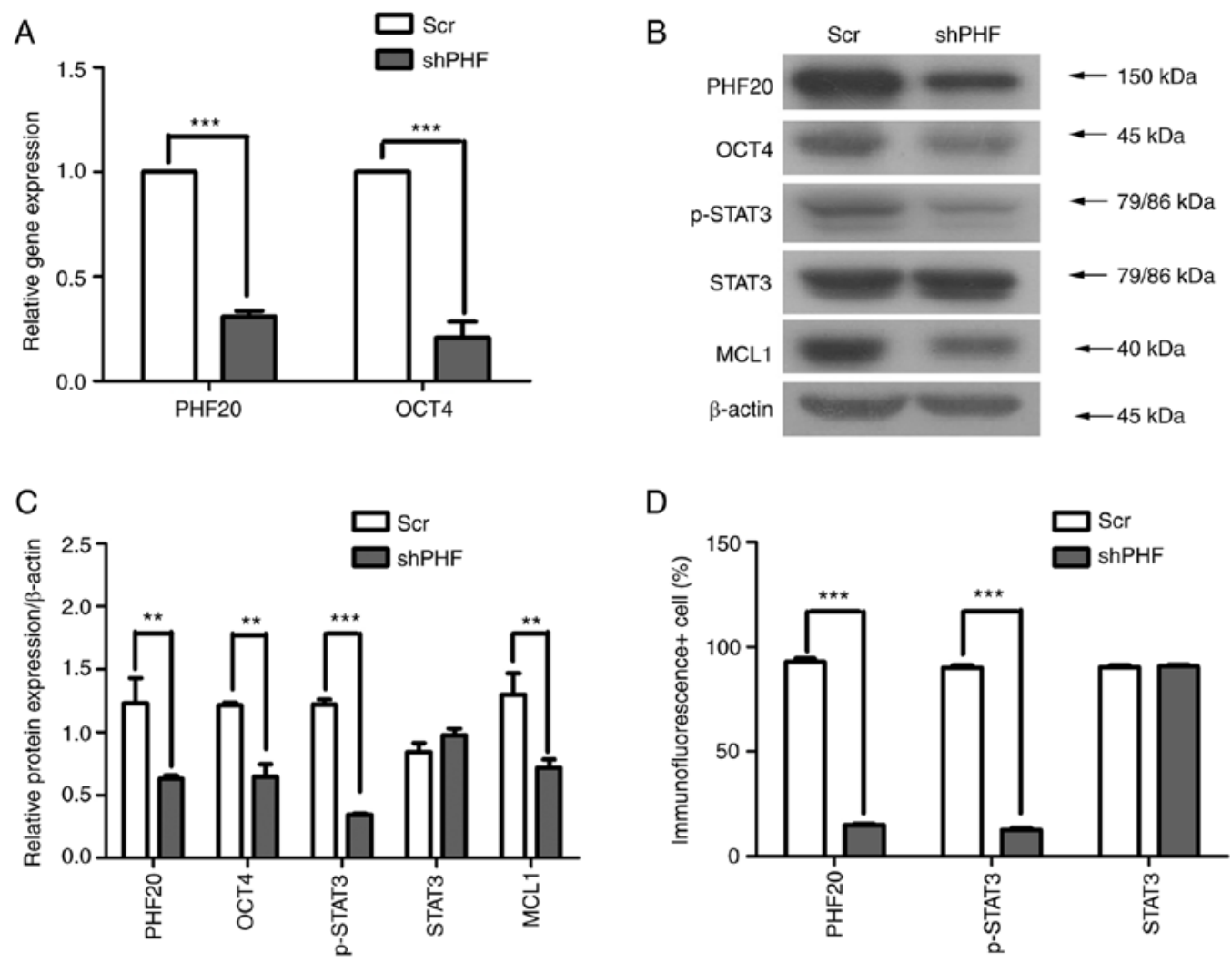

E Scr
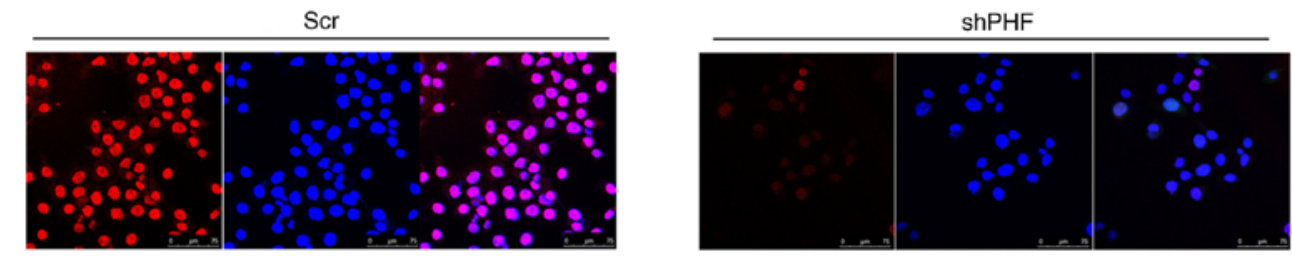

PHF20

DAPI

Merge

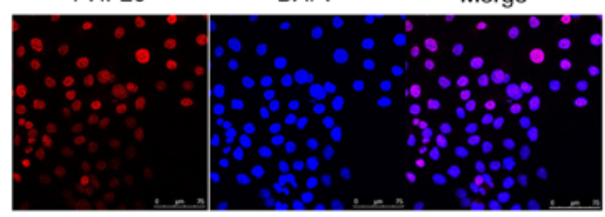

PHF20

DAPI

Merge

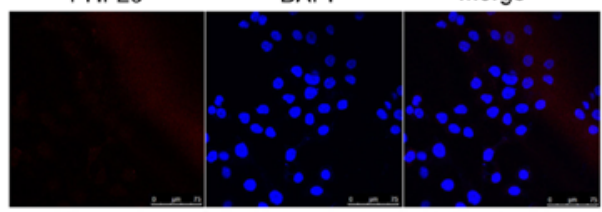

p-STAT3

DAPI

Merge
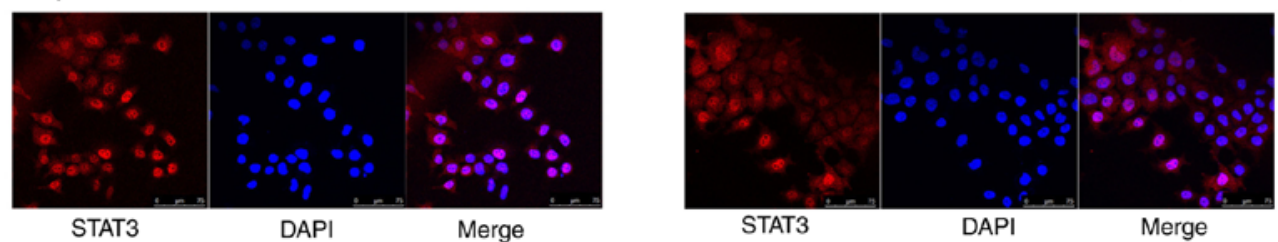

Figure 6. PHF20 silencing decreases the expression levels of its downstream proteins OCT4, MCL1, STAT3 and p-STAT3. (A) The mRNA expression levels of PHF20 and OCT4 were detected by reverse transcription-quantitative PCR in shPHF-transfected and control cells. The results revealed that the mRNA expression levels of OCT4 were markedly decreased following PHF20 knockdown compared with those in the Scr-transfected cells. (B) The protein expression levels of PHF20, OCT4, MCL1, STAT3 and p-STAT3 were determined by western blot assay in shPHF- and Scr-transfected cells. (C) Quantitative analysis of the Western blot results in B. The levels of OCT4, MCL1 and p-STAT3 were downregulated in the shPHF group compared with those in the Scr group. (D) Immunofluorescence assay was used to detect the expression and localization of PHF20, p-STAT3 and STAT3 in shPHF20- and Scr-transfected cells. The results demonstrated that p-STAT3 expression was associated with PHF20. Scale bar, $75 \mu \mathrm{m}$. (E) Quantitative analysis of fluorescent cells in D. Comparison with that in the shPHF group, p-STAT3 expression was lower in FaDu cells following PHF20 knockdown. The experiment was performed in triplicate, and unpaired t-test was used for analysis. ${ }^{* *} \mathrm{P}<0.01$ and ${ }^{* * *} \mathrm{P}<0.001$. PHF20, plant homeodomain finger protein 20 ; shPHF, lentivirus-mediated shRNA targeting PHF20; Scr, scramble shRNA; PARP1, poly(ADP-ribose) polymerase 1; MCL1, myeloid cell leukemia-1; STAT3, phosphorylated signal transducer and activator of transcription 3; p-, phosphorylated; OCT4, octamer-binding transcription factor 4.

of solid tumor, including head and neck cancer, in clinical practice $(36,37)$. However, its clinical efficiency is limited by chemoresistance and side effects, which includes mainly nephrotoxicity and bone marrow toxicity $(29,38)$. Therefore, the molecular mechanisms underlying chemoresistance induced by cisplatin need to be studied in detail. In the present study, the expression levels of PHF20 in FaDu $\mathrm{CIS}_{\mathrm{R}}$ cells were higher compared with those in $\mathrm{FaDu}_{\mathrm{CIS}-\mathrm{S}}$ cells, suggesting that PHF20 
A

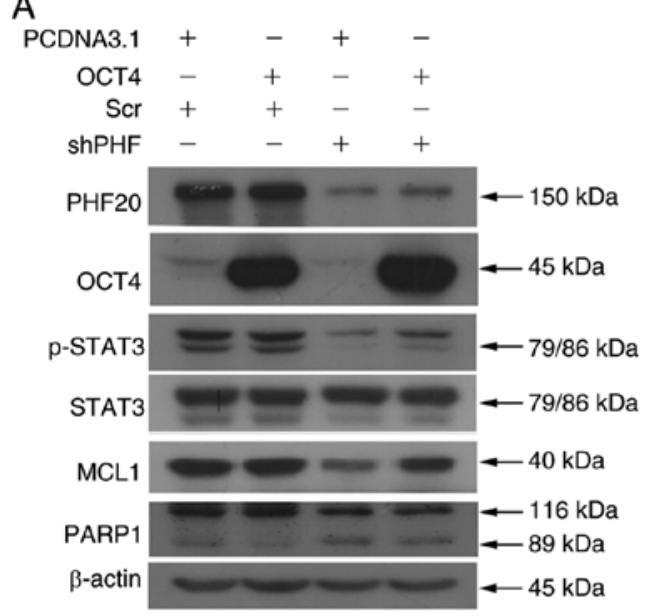

C

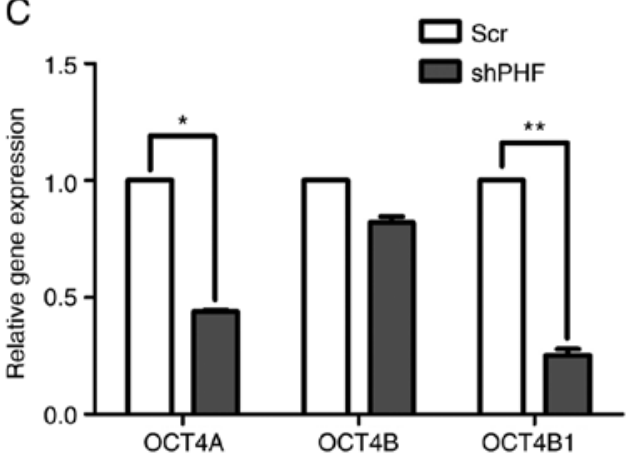

B
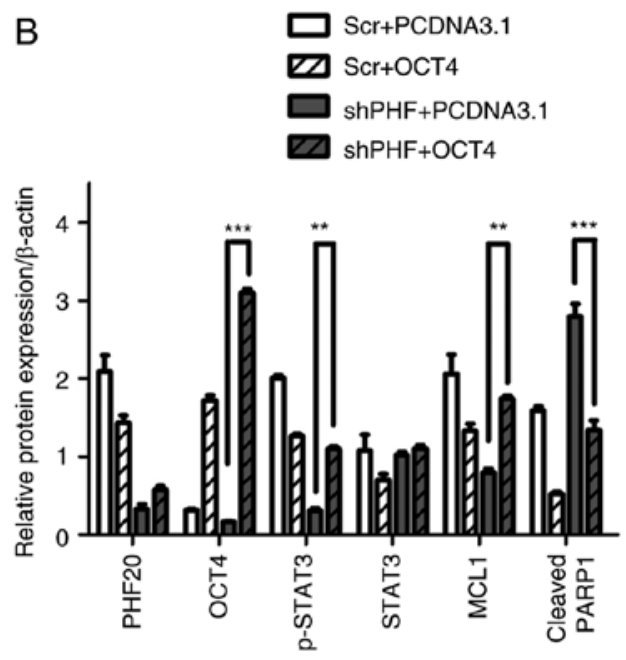

$\mathrm{D}$

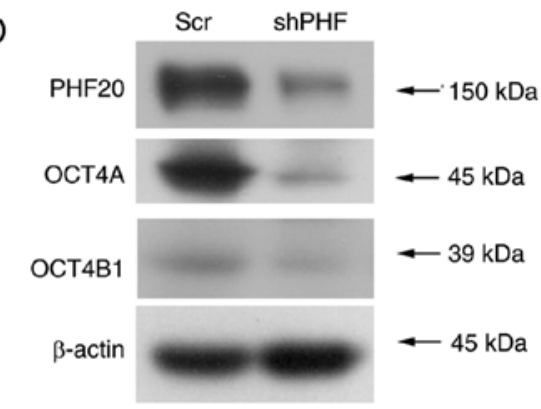

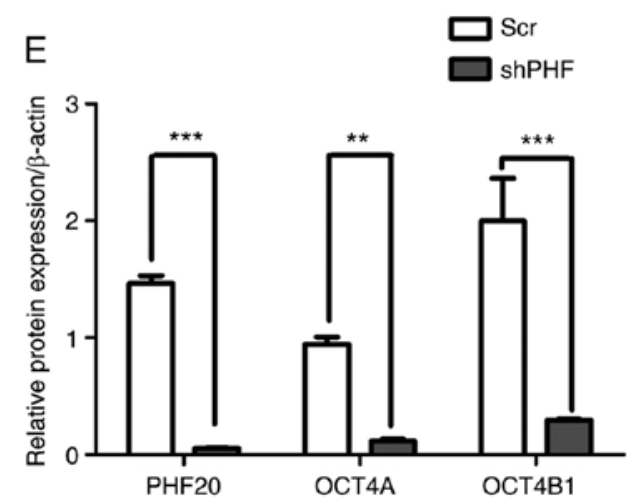

Figure 7. PHF20 regulates apoptosis and improves cisplatin sensitivity via the OCT4-p-STAT3-MCL1 signaling pathway. (A) Western blotting was used to determine the expression levels of PHF20, OCT4, MCL1, PARP1, STAT3 and p-STAT3 in FaDu cells co-transfected with lentivirus-mediated PHF20 shRNA and OCT4 overexpression plasmid. OCT4 overexpression restored the PHF20 knockdown-mediated reduction in the levels of p-STAT3, MCL1 and cleaved PARP1. (B) Quantitative analysis of the western blot results in A. Compared with those in the shPHF + pCDNA3.1 group, the relative levels of p-STAT3 and MCL1 increased, whereas those of cleaved PARP1 decreased in the shPHF + OCT4 group. Mixed model ANOVA was used for analysis. (C) Reverse transcription-quantitative PCR assay demonstrated that the mRNA expression levels of OCT4A and OCT4B1 were decreased, whereas the expression levels of OCT4B were not affected by PHF20 knockdown compared with those in the Scr group. (D) Western blot analysis of OCT4A and OCT4B1 expression levels in the shPHF and control groups. (E) Quantitative analysis of the western blot results in D. Compared with those in the control cells, the relative protein expression levels of OCT4A and OCT4B1 were decreased in the shPHF group. All experiments were performed thrice. ${ }^{* *} \mathrm{P}<0.01$ and ${ }^{* * *} \mathrm{P}<0.001$. PHF20, plant homeodomain finger protein 20; shPHF, lentivirus-mediated shRNA targeting PHF20; Scr, scramble shRNA; PARP1, poly(ADP-ribose) polymerase 1; MCL1, myeloid cell leukemia-1; STAT3, phosphorylated signal transducer and activator of transcription 3; p-, phosphorylated; OCT4, octamer-binding transcription factor 4.

may affect the chemoresistance of HSCC. Notably, PHF20 knockdown attenuated cisplatin resistance and improved the sensitivity of HSCC cells to cisplatin, thus enhancing apoptosis. To further validate the synergistic effect of PHF20 knockdown and cisplatin treatment in vivo, tumor-bearing mice were intravenously injected with cisplatin. No notable tumor regression was observed in the shPHF plus cisplatin group compared with that in the shPHF group (data not shown). This result supported previous findings $(39,40)$, suggesting that FaDu cells were not sensitive to cisplatin treatment in vivo. FaDu cells are the only currently available hypopharyngeal cancer cell line (41). Thus, additional HSCC cell lines are required to validate the results of the present study in vivo. However, the results of the present study demonstrated that PHF20 may serve as a potential marker for cisplatin-resistant HSCC and a therapeutic target to combine with cisplatin to induce cell death.

OCT4 is a key transcriptional factor involved in apoptosis $(23,42,43)$. In the present study, decreased protein 

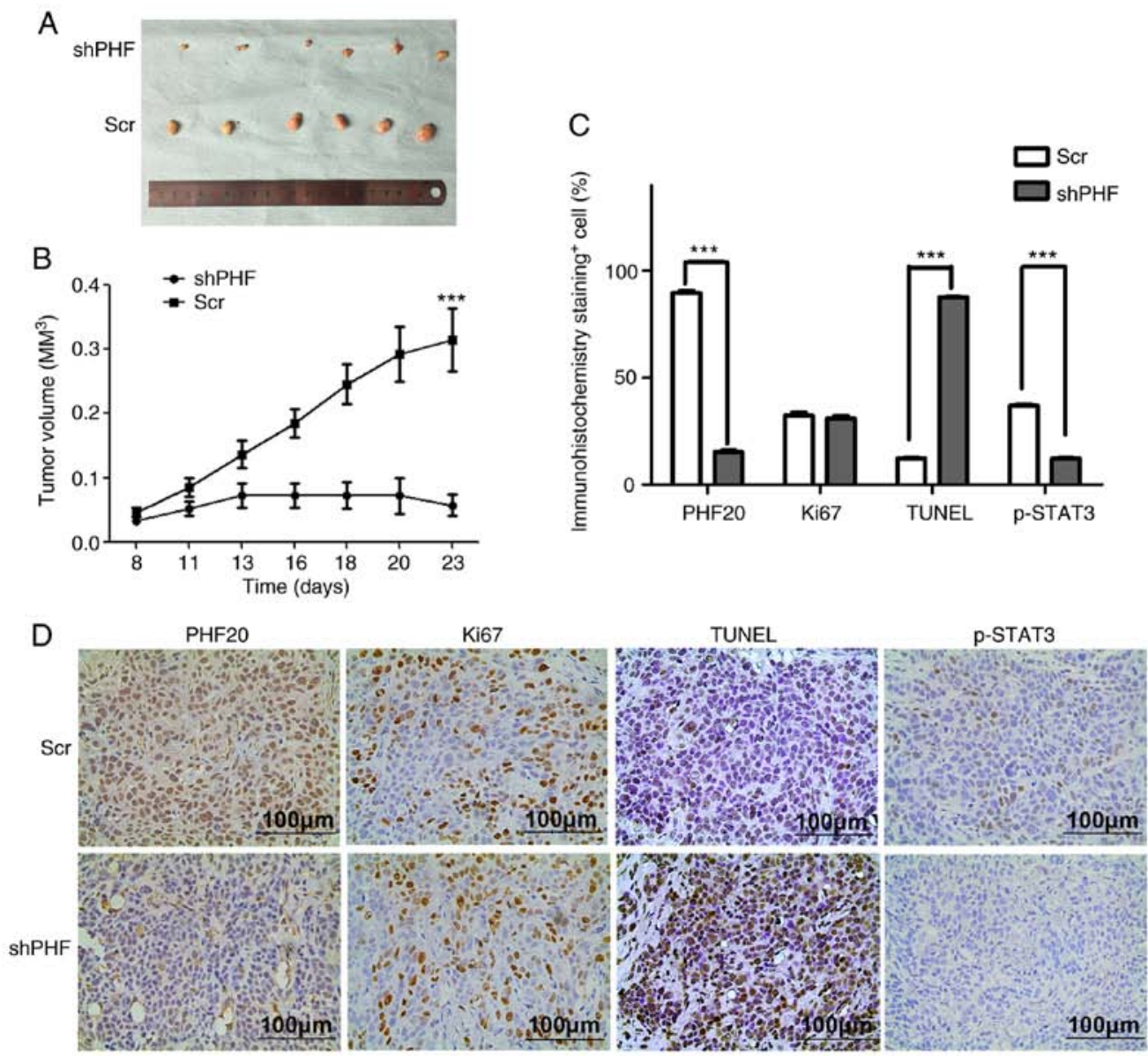

E

Cisplatin

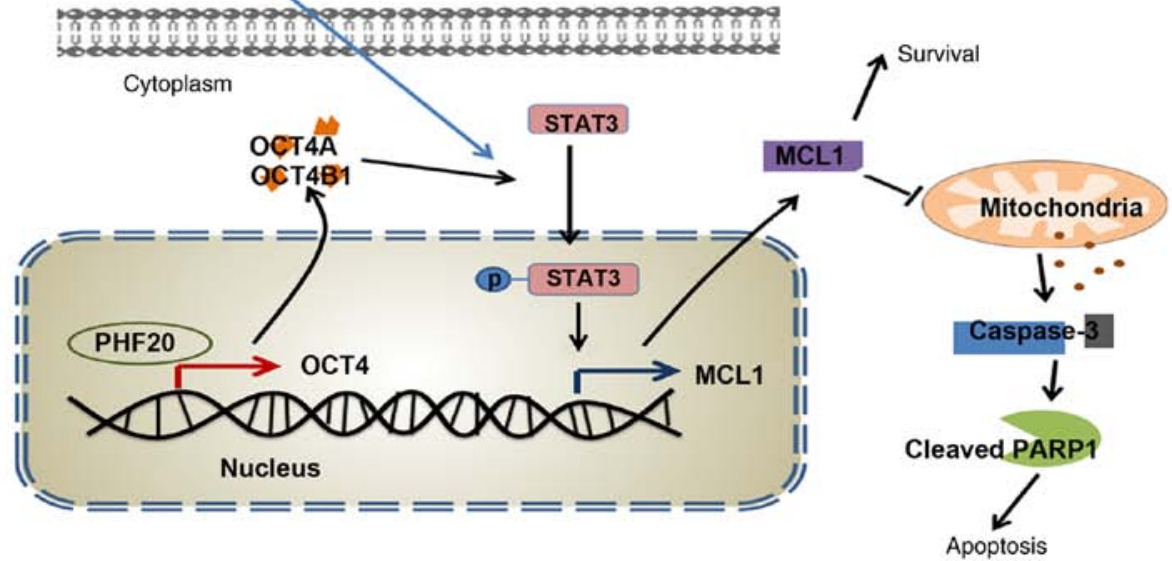

Figure 8. PHF20 inhibition suppresses tumorigenicity via apoptosis in the HSCC cell xenograft model. (A) Representative images of tumors isolated from mice in the shPHF20 and control groups. (B) The tumor growth curves in the two groups. (C) Quantitative analysis of positive cells in (D) the immunohistochemical staining of PHF20, Ki67, TUNEL and p-STAT3 in tumor samples from mice in the two groups. Magnification, x400. Scale bar, $100 \mu \mathrm{m}$. Compared with those in the Scr group, the percentage of apoptotic cells indicated by TUNEL staining was significantly increased, the number of p-STAT3 cells decreased, and the number of Ki67 cells did not obviously differ in the shPHF group. (E) Schematic representation illustrating how the knockdown of PHF20 may synergize with cisplatin to promote apoptosis via the OCT4-p-STAT3-MCL1 signaling pathway. PHF20, plant homeodomain finger protein 20; shPHF, lentivirus-mediated shRNA targeting PHF20; Scr, scramble shRNA; PARP1, poly(ADP-ribose) polymerase 1; MCL1, myeloid cell leukemia-1; casp-3, caspase-3; STAT3, phosphorylated signal transducer and activator of transcription 3; p-STAT3, phosphorylated signal transducer and activator of transcription 3; OCT4, octamer-binding transcription factor 4; TUNEL, terminal deoxynucleotidyl transferase-mediated dUTP-biotin nick end labeling.

expression levels of MCL1 caused by PHF20 knockdown were significantly reversed by co-transfection with a OCT4 overexpression plasmid in FaDu cells. The human OCT4 gene generates three main isoforms, namely OCT4A (44), OCT4B (45) and OCT4B1 (42), by alternative splicing. OCT4A, generally referred to as OCT4, is a pivotal transcriptional factor that sustains the stemness properties of pluripotent cells (46). OCT4B serves an antiapoptotic role in lung adenocarcinoma A549 cells (43). In gastric adenocarcinoma, bladder and brain cancer cell lines, suppression of OCT4B1 induces the upregulation of proapoptotic genes such as cell death-Inducing DFFA-like effector A, and downregulation of antiapoptotic genes such as 
$\mathrm{Bcl} 2$ and Bax (47). The knockdown of OCT4B1 increases the apoptotic rate in gastric cancer due to cell cycle alterations (42). OCT4A induces apoptosis in breast cancer cells (22) and human endometrial cancer (24). PHF20 acts as a transcriptional factor binding to the promotor of OCT4 to promote cellular reprogramming $(14,31)$. However, the role of PHF20 in the regulation of OCT4 isoform expression has not been fully determined. The knockdown of PHF20 remarkably downregulated the mRNA and protein levels of OCT4A and OCT4B1 expression, but did not affect the expression levels of OCT4B compared with those in the Scr group in the present study. Thus, OCT4A and OCT4B1 may mediate PHF20 knockdown-induced apoptosis by regulating the levels of p-STAT3 and MCL1.

In conclusion, PHF20 inhibition may promote apoptosis in FaDu cells via the OCT4-p-STAT3-MCL1 signaling pathway and sensitize FaDu cells to cisplatin treatment.

\section{Acknowledgements}

Not applicable.

\section{Funding}

This work was supported by The National Natural Science Foundation of China (grant nos. 81702679 and 81902763) and Major Programs of Science and Technology Projects in Hainan Province (grant no. ZDKJ202005).

\section{Availability of data and materials}

The RNA sequencing data from the current study has been deposited at the Sequence Read Archive (SRA) database of NCBI (PRJNA705388). Raw data and details of RNA sequencing experiments are available online at https://www. ncbi.nlm.nih.gov/Traces/study/?acc=PRJNA705388. Other datasets used and/or analyzed during the current study are available from the corresponding author on reasonable request.

\section{Authors' contributions}

XiuL and WX conceived, supervised and designed the study. XiuL, ZZ, SK, ZL and SZ performed the experiments. XiuL, XiaL and PJ analyzed the data. SK prepared the figures. XiuL and ZZ wrote the manuscript. XiuL and WX confirm the authenticity of all the raw data. All authors read and approved the final manuscript.

\section{Ethics approval and consent to participate}

The present study was approved by the Committee for the Animal Care and Use of Shandong Provincial ENT Hospital (approval no. XYK-NSFC20190201; Jinan, China).

\section{Patient consent for publication}

Not applicable.

\section{Competing interests}

The authors declare that they have no competing interests.

\section{References}

1. Takes RP, Strojan P, Silver CE, Bradley PJ, Haigentz M Jr, Wolf GT, Shaha AR, Hartl DM, Olofsson J, Langendijk JA, et al: Current trends in initial management of hypopharyngeal cancer: The declining use of open surgery. Head Neck 34: 270-281, 2012.

2. Spector JG, Sessions DG, Haughey BH, Chao KS, Simpson J, El Mofty S and Perez CA: Delayed regional metastases, distant metastases, and second primary malignancies in squamous cell carcinomas of the larynx and hypopharynx. Laryngoscope 111: 1079-1087, 2001.

3. Bova R, Goh R, Poulson M and Coman WB: Total pharyngolaryngectomy for squamous cell carcinoma of the hypopharynx: A review. Laryngoscope 115: 864-869, 2005.

4. Bandu R, Ahn HS, Lee JW, Kim YW, Choi SH, Kim HJ and Kim KP: Liquid chromatography electrospray ionization tandem mass spectrometric (LC/ESI-MS/MS) Study for the identification and characterization of in vivo metabolites of cisplatin in rat kidney cancer tissues: Online Hydrogen/Deuterium (H/D) exchange study. PLoS One 10: e0134027, 2015.

5. Wu DW, Lee MC, Hsu NY, Wu TC, Wu JY, Wang YC, Cheng YW, Chen CY and Lee H: FHIT loss confers cisplatin resistance in lung cancer via the AKT/NF- $\kappa \mathrm{B} /$ Slug-mediated PUMA reduction. Oncogene 34: 2505-2515, 2015.

6. Galluzzi L, Senovilla L, Vitale I, Michels J, Martins I, Kepp O, Castedo M and Kroemer G: Molecular mechanisms of cisplatin resistance. Oncogene 31: 1869-1883, 2012.

7. Degterev A, Boyce M and Yuan J: A decade of caspases. Oncogene 22: 8543-8567, 2003.

8. Adams JM and Cory S: The Bcl-2 apoptotic switch in cancer development and therapy. Oncogene 26: 1324-1337, 2007.

9. Pistritto G, Trisciuoglio D, Ceci C, Garufi A and D'Orazi G: Apoptosis as anticancer mechanism: Function and dysfunction of its modulators and targeted therapeutic strategies. Aging 8: 603-619, 2016.

10. Yu X, Li W, Xia Z, Xie L, Ma X, Liang Q, Liu L, Wang J, Zhou X, Yang Y and Liu H: Targeting MCL-1 sensitizes human esophageal squamous cell carcinoma cells to cisplatin-induced apoptosis. BMC Cancer 17: 449, 2017.

11. Badeaux AI, Yang Y, Cardenas K, Vemulapalli V, Chen K, Kusewitt D, Richie E, Li W and Bedford MT: Loss of the methyl lysine effector protein PHF20 impacts the expression of genes regulated by the lysine acetyltransferase MOF. J Biol Chem 287: 429-437, 2012.

12. Bankovic J, Stojsic J, Jovanovic D, Andjelkovic T, Milinkovic V, Ruzdijic S and Tanic N: Identification of genes associated with non-small-cell lung cancer promotion and progression. Lung Cancer 67: 151-159, 2010.

13. Tang N, Ma L, Lin XY, Zhang Y, Yang DL, Wang EH and Qiu XS: Expression of PHF20 protein contributes to good prognosis of NSCLC and is associated with Bax expression. Int J Clin Exp Pathol 8: 12198-12206, 2015.

14. Long W, Zhao W, Ning B, Huang J, Chu J, Li L, Ma Q, Xing C, Wang HY, Liu Q and Wang RF: PHF20 collaborates with PARP1 to promote stemness and aggressiveness of neuroblastoma cells through activation of SOX2 and OCT4. J Mol Cell Biol 10: 147-160, 2018.

15. Takahashi K, Tanabe K, Ohnuki M, Narita M, Ichisaka T, Tomoda K and Yamanaka S: Induction of pluripotent stem cells from adult human fibroblasts by defined factors. Cell 131: 861-872, 2007.

16. Ji J and Zheng PS: Expression of Sox 2 in human cervical carcinogenesis. Hum Pathol 41: 1438-1447, 2010.

17. Wen J, Park JY, Park KH, Chung HW, Bang S, Park SW and Song SY: Oct4 and Nanog expression is associated with early stages of pancreatic carcinogenesis. Pancreas 39: 622-626, 2010.

18. Wei D, Kanai M, Jia Z, Le X and Xie K: Kruppel-like factor 4 induces p27Kipl expression in and suppresses the growth and metastasis of human pancreatic cancer cells. Cancer Res 68: 4631-4639, 2008.

19. Wang YD, Cai N, Wu XL, Cao HZ, Xie LL and Zheng PS: OCT4 promotes tumorigenesis and inhibits apoptosis of cervical cancer cells by miR-125b/BAK1 pathway. Cell Death Dis 4: e760, 2013.

20. Wang G, Zhou H, Gu Z, Gao Q and Shen G: Oct4 promotes cancer cell proliferation and migration and leads to poor prognosis associated with the survivin/STAT3 pathway in hepatocellular carcinoma. Oncol Rep 40: 979-987, 2018.

21. Meng F, Sun G, Zhong M, Yu Y and Brewer MA: Anticancer efficacy of cisplatin and trichostatin A or 5-aza-2'-deoxycytidine on ovarian cancer. Br J Cancer 108: 579-586, 2013. 
22. Zhang $\mathrm{X}$, Zhang $\mathrm{Y}$, Xu J, Wang $\mathrm{H}$, Zheng $\mathrm{X}$, Lou $\mathrm{Y}$ and Han B: Antigen presentation of the Oct 4 and Sox2 peptides by CD154-activated B lymphocytes enhances the killing effect of cytotoxic T lymphocytes on tumor stem-like cells derived from cisplatin-resistant lung cancer cells. J Cancer 9: 367-374, 2018.

23. Liu X, Ma M, Duan X, Zhang H and Yang M: Knockdown of OCT4 may sensitize NSCLC cells to cisplatin. Clin Transl Oncol 19: 587-592, 2017.

24. Lu CS, Shieh GS, Wang CT, Su BH, Su YC, Chen YC, Su WC, Wu P, Yang WH, Shiau AL and Wu CL: Chemotherapeutics-induced Oct4 expression contributes to drug resistance and tumor recurrence in bladder cancer. Oncotarget 8: 30844-30858, 2017.

25. Kato M, Onoyama I, Yoshida S, Cui L, Kawamura K, Kodama K, Hori E, Matsumura Y, Yagi H, Asanoma K, et al: Dual-specificity phosphatase 6 plays a critical role in the maintenance of a cancer stem-like cell phenotype in human endometrial cancer. Int J Cancer 147: 1987-1999, 2020.

26. Wang L, Feng Z, Wang X and Zhang X: DEGseq: An R package for identifying differentially expressed genes from RNA-seq data. Bioinformatics 26: 136-138, 2010.

27. Goldie FC, Fulton RL, Dawson J, Bluhmki E and Lees KR: Exploration of time-course combinations of outcome scales for use in a global test of stroke recovery. Int J Stroke 9: 755-758, 2014.

28. Livak KJ and Schmittgen TD: Analysis of relative gene expression data using real-time quantitative PCR and the 2(-Delta Delta C(T)) method. Methods 25: 402-408, 2001.

29. Dasari S and Tchounwou PB: Cisplatin in cancer therapy: Molecular mechanisms of action. Eur J Pharmacol 740: 364-378 2014.

30. Czabotar PE, Lessene G, Strasser A and Adams JM: Control of apoptosis by the BCL-2 protein family: Implications for physiology and therapy. Nat Rev Mol Cell Biol 15: 49-63, 2014

31. Zhao W, Li Q, Ayers S, Gu Y, Shi Z, Zhu Q, Chen Y, Wang HY and Wang RF: Jmjd3 inhibits reprogramming by upregulating expression of INK4a/Arf and targeting PHF20 for ubiquitination. Cell 152: 1037-1050, 2013.

32. Liu T, Zhang T, Zhou F, Wang J, Zhai X, Mu N, Park J, Liu M, Liu W, Shang P, et al: Identification of genes and pathways potentially related to PHF20 by gene expression profile analysis of glioblastoma U87 cell line. Cancer Cell Int 17: 87, 2017.

33. Ramezankhani B, Taha MF and Javeri A: Vitamin C counteracts miR-302/367-induced reprogramming of human breast cancer cells and restores their invasive and proliferative capacity. J Cell Physiol 234: 2672-2682, 2019.

34. Zhang D, Ma Q, Shen S and Hu H: Inhibition of pancreatic cancer cell proliferation by propranolol occurs through apoptosis induction: The study of beta-adrenoceptor antagonist's anticancer effect in pancreatic cancer cell. Pancreas 38: 94-100, 2009.

35. Cui G, Park S, Badeaux AI, Kim D, Lee J, Thompson JR, Yan F, Kaneko S, Yuan Z, Botuyan MV, et al: PHF20 is an effector protein of p53 double lysine methylation that stabilizes and activates p53. Nat Struct Mol Biol 19: 916-924, 2012.
36. Qin Z, Ren G, Yuan J, Chen H, Lu Y, Li N, Zhang Y, Chen X and Zhao D: Systemic evaluation on the pharmacokinetics of platinum-based anticancer drugs from animal to cell level: Based on total platinum and intact drugs. Front Pharmacol 10: 1485, 2019.

37. Pointreau Y, Garaud P, Chapet S, Sire C, Tuchais C, Tortochaux J, Faivre S, Guerrif S, Alfonsi M and Calais G: Randomized trial of induction chemotherapy with cisplatin and 5-fluorouracil with or without docetaxel for larynx preservation. J Natl Cancer Inst 101: 498-506, 2009.

38. Knox RJ, Friedlos F, Lydall DA and Roberts JJ: Mechanism of cytotoxicity of anticancer platinum drugs: Evidence that cis-di amminedichloroplatinum(II) and cis-diammine-(1,1-cyclobutanedicarboxylato)platinum(II) differ only in the kinetics of their interaction with DNA. Cancer Res 46: 1972-1979, 1986.

39. Yang J, Ju Z and Dong S: Cisplatin and paclitaxel co-delivered by folate-decorated lipid carriers for the treatment of head and neck cancer. Drug Deliv 24: 792-799, 2016.

40. Khan Z, Khan AA, Prasad GB, Khan N, Tiwari RP and Bisen PS: Growth inhibition and chemo-radiosensitization of head and neck squamous cell carcinoma (HNSCC) by survivin-siRNA lentivirus. Radiother Oncol 118: 359-368, 2016.

41. Bu M, Liu X and Xu W: Upregulation of fascin-1 is involved in HIF-1 $\alpha$-dependent invasion and migration of hypopharyngeal squamous cell carcinoma. Int J Oncol 55: 488-498, 2019.

42. Asadi MH, Mowla SJ, Fathi F, Aleyasin A, Asadzadeh J and Atlasi Y: OCT4B1, a novel spliced variant of OCT4, is highly expressed in gastric cancer and acts as an antiapoptotic factor. Int J Cancer 128: 2645-2652, 2011.

43. Cortes-Dericks L, Yazd EF, Mowla SJ, Schmid RA and Karoubi G: Suppression of OCT4B enhances sensitivity of lung adenocarcinoma A549 cells to cisplatin via increased apoptosis. Anticancer Res 33: 5365-5373, 2013.

44. Li SW, Wu XL, Dong CL, Xie XY, Wu JF and Zhang X: The differential expression of OCT4 isoforms in cervical carcinoma. PLoS One 10: e0118033, 2015.

45. Wang X, Zhao Y, Xiao Z, Chen B, Wei Z, Wang B, Zhang J, Han J, Gao Y, Li L, et al: Alternative translation of OCT4 by an internal ribosome entry site and its novel function in stress response. Stem Cells 27: 1265-1275, 2009.

46. Tsai SC, Chang DF, Hong CM, Xia P, Senadheera D, Trump L, Mishra S and Lutzko C: Induced overexpression of OCT4A in human embryonic stem cells increases cloning efficiency. Am J Physiol Cell Physiol 306: C1108-1118, 2014

47. Mirzaei MR, Najafi A, Arababadi MK, Asadi MH and Mowla SJ: Altered expression of apoptotic genes in response to OCT4B1 suppression in human tumor cell lines. Tumour Biol 35: 9999-10009, 2014.

This work is licensed under a Creative Commons Attribution-NonCommercial-NoDerivatives 4.0 International (CC BY-NC-ND 4.0) License. 